\title{
Commentary
}

\section{Nutrition and public health in medical education in the UK: reflections and next steps}

\author{
Jonathan Broad ${ }^{1,2, *}$ and Megan Wallace ${ }^{2}$ \\ ${ }^{1}$ School of Social and Community Medicine, University of Bristol, Bristol BS8 2PN, UK: ${ }^{2}$ Peninsula Medical School, \\ University of Plymouth, Plymouth, UK
}

Submitted 4 January 2018: Final revision received 21 February 2018: Accepted 2 March 2018; First published online 30 April 2018

\begin{abstract}
Objective: Doctors play an important role in the identification of nutritional disorders and as advocates for a healthy diet, and although the key tenets of good nutrition education for medical students have been discussed, reports on implementation are sparse. The present commentary responds to a gap in UK medical students' understanding of nutrition and public health and suggests ways to improve it.

Design: We review literature about nutrition education in medical schools and discuss a 6-week elective in public health nutrition for medical students. We discuss suggested competencies in nutrition and compare means of students' confidence and knowledge before and after.

Setting: A nutrition and public health elective in a UK medical school, discussing advocacy, motivational interviewing, supplements, nutritional deficits, parenteral nutrition, obesity services. We utilised multidisciplinary teaching approaches including dietitians, managers and pharmacists, and students implemented a public health activity in a local school.

Subjects: Fifteen final-year medical students were enrolled; sixty school pupils participated in the public health activity.

Results: The students were not confident in nutrition competencies before and were taught less than European counterparts. Students enjoyed the course, had improved knowledge, and felt more confident in interviewing and prescribing supplements. Feedback from the local school was positive.

Conclusions: Students in our UK medical school were not confident in their required competencies within the confines of the current educational programme. An elective course can improve medical students' knowledge. Similar courses could be implemented in other medical schools to improve nutrition and public health knowledge and practice in future doctors.
\end{abstract}

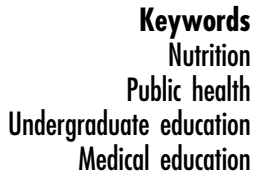

Nutrition

Public hedth Medical education
This commentary responds to a gap in knowledge that UK medical students have about nutrition as they enter the foundation programme and suggests ways to improve it. Nutrition and diet is a key contributor to the growing trend of obesity in children and contributes to a lifelong disease burden associated with the metabolic effects ${ }^{(1,2)}$. Diet-related factors are a major risk factor for CVD in adults, which is a significant cause of morbidity alongside cancer in European countries ${ }^{(3)}$. Healthy nutrition is a manageable risk factor; patients listen to doctors' advice and subsequently may improve their diets ${ }^{(4)}$. Doctors in Europe are fortunate to work within multidisciplinary specialist teams to improve the nutritional health of both healthy and sick individuals, including dietitians and nurses. According to the Academy of Medical Royal Colleges (UK), doctors in the early stages of their training should know about nutrition in normal growth and health, public health aspects of nutrition and the relationship between nutrition and disease ${ }^{(5)}$. In practice, nutrition education lags behind and students are not confident in managing and preventing poor nutrition. Here, we outline current best practice in undergraduate education about nutrition, where medical schools fall behind, and discuss a nutrition curriculum in our medical school that incorporates active health promotion outreach into a local school. 
Box 1 UK undergraduate curriculum in nutrition, Academy of Medical Royal Colleges UK, 2011 ${ }^{(5)}$

All newly qualified doctors should be able to:

1. Understand how nutrition, diet and physical activity influence health and disease;

2. Understand how disease and its management can compromise nutritional health;

3. Recognise nutritional risk and assess nutritional state; and

4. Be safe and competent to advise on and, under supervision, manage nutrition, hydration and physical activity in health and disease.

\section{Undergraduate education about nutrition in the UK and beyond}

In 2013 the intercollegiate group on nutrition of the Academy of Medical Royal Colleges (UK) published a curriculum of undergraduate competencies in nutrition, stating that new doctors should be able to understand how nutrition influences health and disease, how disease compromises nutrition, and be safe and competent in recognising and managing nutrition and hydration for both under- and overnutrition ${ }^{(5)}$. Moreover, the General Medical Council states that all medical students are expected to 'discuss the role of nutrition in health' ${ }^{,(6)}$. Suggested competencies as argued by the Academy of Medical Royal Colleges are described in Box 1. A recent European-wide survey found that UK medical schools teach an average of $22 \mathrm{~h}$ of nutrition throughout the medical curriculum, slightly lower than the European average but higher than the US average ${ }^{(7)}$.

\section{Local experience in Peninsula Medical School}

Before our intervention, our medical school (Peninsula Medical School) taught about $20 \mathrm{~h}$ of nutrition within a spiral curriculum predominantly within biomedical sciences. The curriculum focused on physiology and pathophysiology within problem-based learning biomedical sciences, and there was less focus on clinical and public health aspects such as metabolic status, management of under- and overnutrition, or health promotion. We found that final-year medical students and first-year doctors were not confident in clinical and public health aspects of nutrition on a 7-item survey (mean confidence $=2 \cdot 89 / 5$, $95 \%$ CI $2 \cdot 64,3 \cdot 15$ ) and were least confident in managing parentally fed patients and hydration. We implemented a 6-week elective course for fifteen medical students including $8 \mathrm{~h}$ of teaching and practicals in nutrition, with a focus on paediatrics, culminating in a $3 \mathrm{~h}$ student-led outreach event for sixty pupils in a local school. This
Table 1 Case study of a clinical course in nutrition for final-year medical students

\begin{tabular}{|c|c|}
\hline Topics & Methods \\
\hline $\begin{array}{l}\text { Pathophysiology of poor diet and } \\
\text { physiology of healthy diets }(1 \mathrm{~h})\end{array}$ & Small group lecture \\
\hline $\begin{array}{l}\text { Biopsychosocial aspects } \\
\text { of diet }(1 \mathrm{~h})\end{array}$ & $\begin{array}{l}\text { Small group lecture with student- } \\
\text { led case discussions }\end{array}$ \\
\hline $\begin{array}{l}\text { Communication and } \\
\text { motivational interviewing in } \\
\text { under- and overnutrition ( } 1 \mathrm{~h})\end{array}$ & $\begin{array}{l}\text { Small group lecture with student- } \\
\text { led activities }\end{array}$ \\
\hline $\begin{array}{l}\text { Recognising risk of } \\
\text { malnourishment and nutrition } \\
\text { state }(2 \mathrm{~h})\end{array}$ & $\begin{array}{l}\text { Small group lecture with student- } \\
\text { led case discussions }\end{array}$ \\
\hline $\begin{array}{l}\text { Management of nutrition in } \\
\text { clinical practice }(1 \mathrm{~h})\end{array}$ & $\begin{array}{l}\text { Small group lecture with student- } \\
\text { led case discussions and } \\
\text { activities }\end{array}$ \\
\hline $\begin{array}{l}\text { Multidisciplinary treatment of } \\
\text { obesity }(2 \mathrm{~h})\end{array}$ & $\begin{array}{l}\text { Small group lecture with student- } \\
\text { led discussions and activities }\end{array}$ \\
\hline $\begin{array}{l}\text { Workshop in a local school } \\
\text { about healthy eating }(3 \mathrm{~h})\end{array}$ & $\begin{array}{l}\text { Student-led design session } \\
\text { followed by student-led public } \\
\text { health workshop in a local } \\
\text { school using presentations, } \\
\text { activities and games }\end{array}$ \\
\hline
\end{tabular}

curriculum was designed to bridge the gap between physiology and clinical practice, focusing on healthy diets and mechanisms of nutrition-based pathophysiology, motivational interviewing techniques to improve healthy eating, clinical management of malnourishment, and public health aspects of nutrition and obesity (see Table 1). The course utilised a variety of approaches, including traditional small group lectures, workshops with student activities driving the learning, and practicals where students designed a public health intervention. Doctors, dietitians and clinical psychologists led the teaching. Subsequently students led a healthy eating workshop in a local school. Following the course students felt more confident about nutrition (paired improvement $=0 \cdot 84$, $P=0.049)$ and had an improvement on a multiple-choice question about nutrition from 4.5 to 9 out of 10 (Wilcoxon signed rank $W<0.001)$. In a focus group, students felt that the curriculum was relevant to their future work and felt more confident about managing in practice. We are rolling out elements of this course for foundation doctors and future medical students.

\section{Conclusions and priorities for education and research}

Nutrition education in our medical school was focused largely in preclinical science and did not support students to become competent in managing and preventing the disease burden associated with poor nutrition prior to the establishment of our course. Students and foundation doctors were unconfident, although this improved with $11 \mathrm{~h}$ of teaching and practicals on nutrition, clinical management, and public health and health promotion. We would like to build on this course by making it available to a wider number of students, offering a longer 
elective, and to build on wider social factors affecting nutrition, including the connection between food systems and environmental health, and public health policy in the food industry. We believe that enabling students to understand the individual and social determinants of food and diet will enable our cohort to better understand, prevent and treat the health consequences of malnutrition and obesity. More widely, we hope that our students will become advocates for a healthy food system. Our impact is limited, however, by the small scale and self-elected nature of the current intervention. We believe that our local experience is similar to that of other centres and encourage medical educators to broaden the scope of their curriculum to include clinical and public health components of nutrition. We believe expansion of current teaching in health professionals is necessary to meet the large burden of nutrition-related disease. This will support doctors to meet the General Medical Council's expectations and equip future health professionals with the skills to manage poor nutrition and promote healthy eating in the patient population.

\section{Acknowledgements}

Acknowledgements: The authors thank Professor Majeed and Dr Waters for their help in the project. Financial support: This work was done as part of educational responsibilities by the lead author in his paid full-time position in a teaching hospital in the National Health Service, UK. The authors declare no financial support for this research. Conflict of interest: The authors declare no conflicts of interest. Authorship: J.B. established the teaching programme, envisaged and co-wrote the article and analysed the data. M.W. taught on the teaching programme and co-wrote the article. Ethics of buman subject participation: This intervention and evaluation was performed as part of routine educational activities. Our faculty routinely evaluates educational activities and, as such, ethics was not sought.

\section{References}

1. Hill JO \& Peters JC (1998) Environmental contributions to the obesity epidemic. Science 280, 1371-1374.

2. Gardner DS, Hosking J, Metcalf BS et al. (2009) Contribution of early weight gain to childhood overweight and metabolic health: a longitudinal study (EarlyBird 36). Pediatrics 123 , e67-e73.

3. Townsend N, Wilson L, Bhatnagar P et al. (2016) Cardiovascular disease in Europe: epidemiological update 2016. Eur Heart J 37, 3232-3245.

4. Rudolf M (2009) Tackling obesity through the Healthy Child Programme: a framework for action. http://www.ukhealth forum.org.uk/prevention/pie/?entryid43=20791\&cid $=150692$ \&char=R (accessed December 2017).

5. Academy of Medical Royal Colleges (2013) UK Undergraduate Curriculum in Nutrition. http://www.aomrc.org.uk/ publications/reports-guidance/uk-undergraduate-curriculumnutrition/ (accessed December 2017).

6. General Medical Council (2015) Outcomes for graduates (Tomorrow's Doctors). https://www.gmc-uk.org/-/media/ documents/outcomes-for-graduates-jul-15-1216_pdf-61408029. pdf (accessed April 2018).

7. Chung M, Buul VJ, Wilms E et al. (2014) Nutrition education in European medical schools; results of an international survey. Eur J Clin Nutr 68, 844-846. 